\title{
Ecotoxicological assessment of underwater welding impact during the construction of marine pipelines
}

\author{
K.Y. Kirichenko, K.S. Pikula, A.M. Zakharenko \& A.V. Gridasov \\ Far Eastern Federal University, Vladivostok, Russian Federation \\ S.G. Parshin \\ Peter the Great St. Petersburg Polytechnic University, Saint Petersburg, Russian Federation
}

S.A. Medvedev

Stock Company «Izumrud», Vladivostok, Russian Federation

I.A. Vakhniuk

Far Eastern Federal University, Vladivostok, Russian Federation

K.S. Golokhvast

Far Eastern Federal University, Vladivostok, Russian Federation

N.I. Vavilov All-Russian Institute of Plant Genetic Resources, Saint-Petersburg, Russian Federation

Pacific Geographical Institute FEB RAS, Vladivostok, Russian Federation

\begin{abstract}
Underwater welding is commonly used in joining pipelines and in underwater construction. Harmful and hazardous compounds are added to many flux cored wires for underwater welding and cutting, which can have a negative impact on marine life. This study is the first attempt to determine the influence of underwater welding on marine organisms using a standard model for assessing the changes in the early development of embryos of the sea urchin Scaphechinus mirabilis during short-term cultivation with the postulated toxicant.

Particles emitted during underwater welding pose toxicological threat to marine ecosystems. This fact requires the development of regulatory documents in the field of environmental protection and the introduction of compensatory measures to reduce the impact on marine organisms.
\end{abstract}

\section{INTRODUCTION}

The construction of long-distance subsea oil and gas pipelines has become a trend in the development of networks of large corporations. To date, several major underwater projects have been completed or currently are under development worldwide, including the Russian Federation:

1. Nord Stream $(1,224 \mathrm{~km})$ and Nord Stream $2(1,200 \mathrm{~km})$ - gas pipelines between Russia and Germany running over the bottom of the Baltic Sea;

2. The Blue Stream $(1,213 \mathrm{~km})$ and the Turkish Stream $(1,100 \mathrm{~km})$ - gas pipelines between Russia and Turkey running over the bottom of the Black Sea;

3. The Langeled pipeline $(1,200 \mathrm{~km})$ connecting the Norwegian Ormen Lange natural gas field with the U.K. Easington Gas Terminal;

4. Dzhubga - Lazarevskoye - Sochi $(166 \mathrm{~km})$ - a system of gas pipelines for energy supply in Sochi.

Underwater welding is commonly used in joining of the pipelines and in underwater construction (Labanowski et al., 2008). Underwater welding was first demonstrated in 1932 by the Soviet engineer K.K. Khrenov (Khrenov \& Livshiz,1934). 
The compositions, electrodes and methods of this technology are being improved till this day (Han et al., 2020; Park \& Moon, 2020). Commonly, various additives are introduced to the flux cored wire to improve the technology (Xing et al., 2020). For working in deep water, toxic materials, for instance, chromium oxides, metallic chromium, and potassium dichromate $\left(\mathrm{K}_{2} \mathrm{Cr}_{2} \mathrm{O}_{7}\right)$ are added. The introduction of dichromate, for example, reduces the ionization potential and improves the stability of arcing under water, as well as increases the mechanical properties of welded joints during the underwater welding (Grishanov \& Pankov, 1994a; Yushchenko et al., 1995; Duo et al., 2014).

As is known, $\mathrm{K}_{2} \mathrm{Cr}_{2} \mathrm{O}_{7}$ is a strong oxidizing agent with a pronounced genotoxic effect and it is used as a reference toxicant in aquatic toxicity testing (Kikuchi et al., 2017; Patlolla et al., 2009; Pikula et al., 2019). When welding, potassium dichromate, as well as oxidizing metallic chromium, form toxic chromium oxides in a gas-vapor bubbles. Metal fluorides (lithium and cobalt) are also added to the composition of flux cored wire and electrodes for underwater welding (Grishanov \& Pankov, 1994b).

A flux cored wire for welding steels under water is known, which includes a powder mixture containing loparite concentrate, cadmium oxide and nickel. The wire improves the quality and corrosion resistance of weld joints, however, it contains cadmium oxide and radioactive thorium oxide $\mathrm{ThO}_{2}$ (in loparite concentrate) (Grishanov \& Pankov, 1994c). Barium peroxide (Wang et al., 2012) and potassium chlorate $\mathrm{KClO}_{3}$ (Duo et al., 2015) are also among the components of flux cored wire for underwater arc cutting. In summary, many flux cored wires for underwater welding and cutting contain harmful and hazardous compounds that can have a negative effect on marine life.

Previously we have shown a dependence of aquatic toxicity of welding fume particles on the welding electrode type and the welding regime parameters using a microalgae growth-inhibition approach (Kirichenko et al., 2019). In this study, we assessed the environmental impact of the SEAWELD electrode (Arcair) used for underwater welding on early development of the sea urchin embryos Scaphechinus mirabilis during short-term cultivation.

\section{MATERIALS AND METHODS}

\subsection{Sample preparation}

The practical application of underwater welding is complicated by several factors, including poor visibility, which in turn makes it difficult to make butt joints as the welding path is easily lost. In this regard, during the experiment, a fillet weld of lap joint was performed, and the edges of plates were used as guides for the electrode.

As it known, water-cooled electrode covering melts slower than the core wire forming a "fingernail" at the end of the electrode, which, in turn, ensures the stability of gas bubble and arc burning. Therefore, the welding was done by supported electrode while moving the electrode along the weld line and touching the metal surface with the protruding edge of the "fingernail" at the end of electrode. We moved the electrode along the welding path without lateral oscillations and with the speed that provided the desired cross section of weld metal.

In the welding experiment, we used 5-mm thick metal plates from commercial quality carbon steel, Russian standard VSt3sp according to GOST 19903-74. Chemical composition of used steal represented in Table 1.

The welding was done in the lower position at direct-current straight polarity $\left(\mathrm{I}_{\text {welding }}=120\right.$ A) with the Arcair Sea-Weld electrodes (Victor Technologies, USA), $3.2 \mathrm{~mm}$ in diameter, $356 \mathrm{~mm}$ in length (1/8 “x14"). The electrode covering has three layers: iron oxide, aluminum, and plasticized vinyl (Figure 1).

Seawater for the experiment was taken in the Ajax Bay (Russky Island, Vladivostok) in 40liter sterile containers. We filtered the collected water through $0.45 \mu \mathrm{m}$ filters and poured it into a 160-liter glass aquarium (Figure 2). 
Table 1. Chemical composition (\%) of steel VSt3sp.

\begin{tabular}{llllllllll}
\hline $\mathrm{C}$ & $\mathrm{Si}$ & $\mathrm{Mn}$ & $\mathrm{Ni}$ & $\mathrm{S}$ & $\mathrm{P}$ & $\mathrm{Cr}$ & $\mathrm{Cu}$ & $\mathrm{As}$ & $\mathrm{Fe}$ \\
\hline $0.14-0.22$ & $0.12-0.3$ & $0.4-0.65$ & $<0.3$ & $<0.05$ & $<0.04$ & $<0.3$ & $<0.3$ & $<0.08$ & $<100$ \\
\hline
\end{tabular}

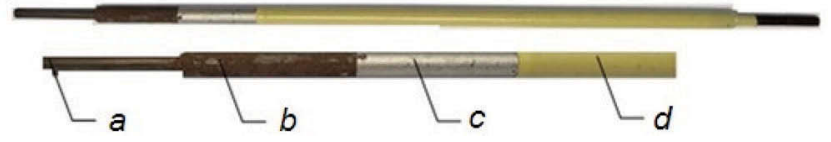

Figure 1. The structure of the Arcair Sea-Weld electrode; $a$ - electrode core wire, $b$ - iron oxide layer, $\mathrm{c}$-aluminum covering, $\mathrm{d}$ - plasticized vinyl.
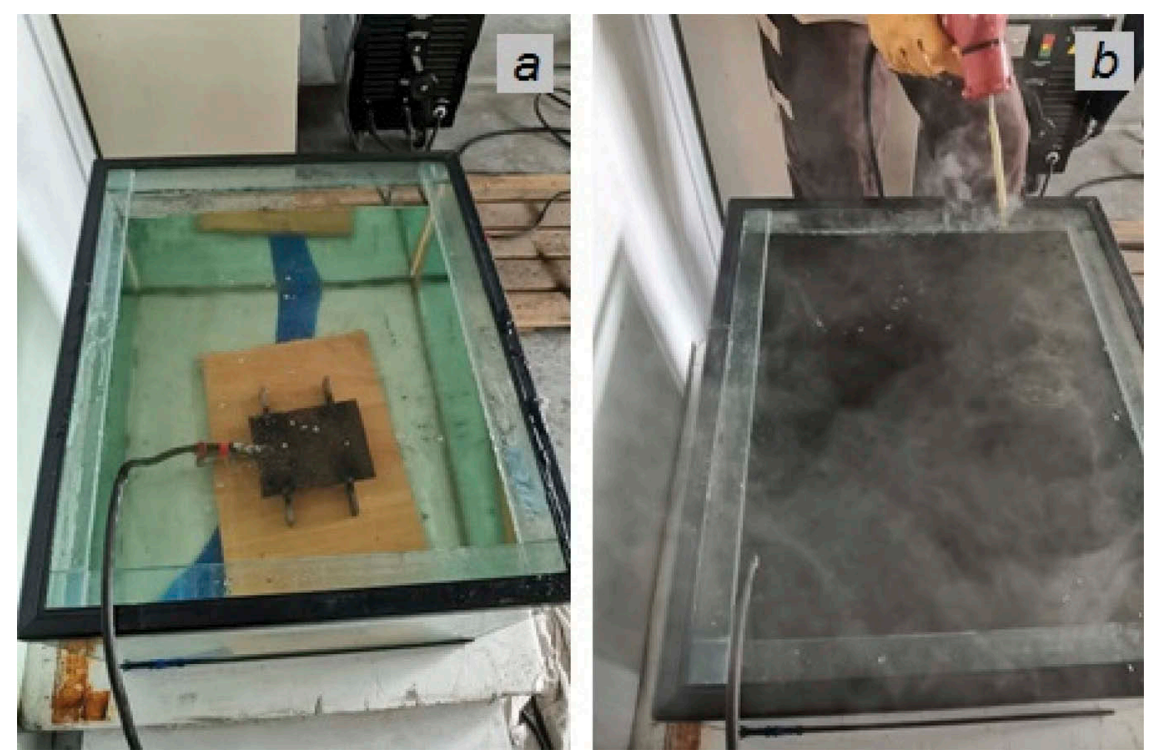

Figure 2. The experimental aquarium used for simulating underwater welding; $\mathrm{a}$ - before burning of an electrode, $\mathrm{b}$ - after burning of an electrode $(60 \mathrm{sec})$.

We measured the particle size distribution of the welding fume generated above the aquarium using a TSI 9306 V2 particle counter (Aerotrack, USA) at time intervals of 15, 30, 45, and 60 seconds.

We collected sea water samples from the experimental aquarium at 15, 30, 45, and 60 seconds after the start of the underwater welding experiment. The particle size analysis of the obtained sea water samples was performed in the particle range of 1-700 $\mu \mathrm{m}$ using the Analysette 22 NanoTec plus laser particle sizer (Fritsch GmbH, Germany). Additionally, we carried out particle size analysis of seawater in the range of 100-900 nm by the CytoFLEX flow cytometer (Beckman Coulter, USA) using the data of forward scattering of violet laser (405 $\mathrm{nm})$.

The experiments were carried out in the Department of Welding and in the Education and Scientific Center of Nanotechnology, School of Engineering of the Far Eastern Federal University.

\subsection{Aquatic toxicity assessment}

Aquatic toxicity of underwater welding suspensions was evaluated by standard early embryo growth toxicity test (Nacci et al., 1986) using the sea urchin S. mirabilis A. Agassiz, 1864 
(Kroh and Mooi, 2015). Sea urchin embryos were incubated in 24 -well plates at $17-17.5^{\circ} \mathrm{C}$, water salinity of $33.7 \%$, and $\mathrm{pH}$ of 8.18 . The aliquot of embryonic cells in seawater was $1000 \mu \mathrm{l}$. We added the welding suspension, which was obtained after 60 seconds of simulating the underwater welding, in volumes of $1,10,100,250,500$, and $1000 \mu \mathrm{l}$. In all cases, the volume of added liquid was brought to $1000 \mu$ using seawater filtered by the method described above. Accordingly, at the maximum concentration, only welding suspension was added to the aliquot of sea urchin embryos, and seawater without welding suspension was used as a control.

We observed early changes in the development of sea urchin embryos using the Axio Observer A1 optical microscope (Carl Zeiss, Germany) for 48 hours. Control points were recorded after 2, 4, 6, 24, and 48 hours of exposure of the eggs and sperm of the sea urchin in the tested suspensions of underwater welding particles.

\section{RESULTS AND DISCUSSION}

One of the drawbacks of the model used is the small depth of the aquarium compared to the real underwater welding conditions. As a result, a certain amount of welding aerosol was emitted into the air, which obviously would remain in the water medium when welding at great depths. The particle size composition of the welding aerosol emitted into the air above the aquarium during the experiment presented in Table 2.

According to the data presented in Table 2, there was a significant increase in the concentration of particles with the diameter of 0.3 to $3 \mu \mathrm{m}$ in the air above the underwater welding process. The concentration of $0.3 \mu \mathrm{m}$ particles increased 100 times in 60 seconds after the start of the experiment compared to the control concentration. At the same time, the concentrations of $0.5 \mu \mathrm{m}$ and $1 \mu \mathrm{m}$ particles increased 500 times. Obviously, when welding at a depth, all these particles will remain in the water.

Even though a part of the welding aerosol was emitted into the air, most of the solid particles emitted during the underwater welding remained in sea water. The particle size distribution of the welding suspensions in the range of 1-700 $\mu \mathrm{m}$ represented in Table 3 .

As we can see, seawater is an extremely heterogeneous and complex system. The laser diffraction method does not allow us to clearly verify the nano- and microparticles of welding suspension, therefore we additionally used flow cytometry to identify the particle sizes with higher precision. The particle size distribution of suspensions obtained using the CytoFLEX flow cytometer is shown in Figure 3.

Firstly, we can draw a preliminary conclusion about the necessity to create a combined precision method for measuring the dimensions, concentration and fractional ratio of welding aerosol particles in sea water. Since, to date, none of the methods can accurately determine both the concentration and dimensions of nanoparticles in sea water.

Table 2. Particle size composition of the aerosol emitted during the simulation of underwater welding.

\begin{tabular}{llrrrr}
\hline & $\begin{array}{l}\text { Control (air before } \\
\text { the experiment), } \\
\text { particles in } \mathrm{m}^{3}\end{array}$ & \multicolumn{3}{l}{ Welding aerosol during the experiment, particles in $\mathrm{m}^{3}$} \\
\cline { 3 - 6 } & $15 \mathrm{sec}$ & $30 \mathrm{sec}$ & $45 \mathrm{sec}$ & $60 \mathrm{sec}$ \\
\hline 0.3 & 22880 & 90598 & 263575 & 720336 & 2302992 \\
0.5 & 3406 & 16091 & 146790 & 488030 & 1750635 \\
1 & 1365 & 7615 & 26060 & 100030 & 715639 \\
3 & 376 & 2742 & 785 & 1541 & 54096 \\
5 & 201 & 1467 & 366 & 568 & 9424 \\
10 & 35 & 351 & 63 & 100 & 71 \\
\hline
\end{tabular}


Table 3. Particle size composition of the welding aerosol suspension in sea water obtained using the Fritch laser particle sizer.

\begin{tabular}{lccccc}
\hline & $\begin{array}{l}\text { Control (sea } \\
\text { water), } \% \text { of } \\
\text { particles }\end{array}$ & \multicolumn{4}{l}{$\begin{array}{l}\text { The distribution of solid particles in the welding sus- } \\
\text { pension during the experiment, } \%\end{array}$} \\
\cline { 3 - 6 } Particle size, $\mu \mathrm{m}$ & $15 \mathrm{sec}$ & $30 \mathrm{sec}$ & $45 \mathrm{sec}$ & $60 \mathrm{sec}$ \\
\hline$<1$ & 0.3 & 1.9 & 2.7 & 3.5 & 3.4 \\
10 & 11.9 & 21.1 & 9.4 & 8.1 & 6.5 \\
50 & 0.3 & 9.7 & 9.8 & 11.9 & 38.3 \\
100 & 0 & 3.8 & 0.5 & 0.7 & 0.8 \\
400 & 0.9 & 15.6 & 2.7 & 19.8 & 18 \\
700 & 37 & 23.8 & 36.2 & 22.8 & 22.5 \\
$>700$ & 49.6 & 24.1 & 38.7 & 23.2 & 10.7 \\
\hline
\end{tabular}

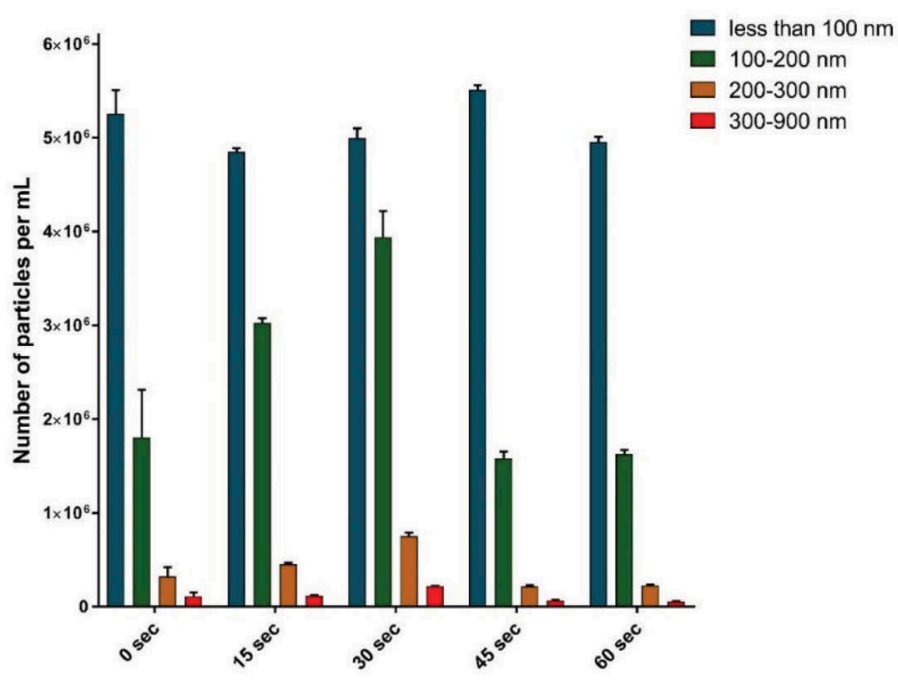

Figure 3. Particle size composition of the welding aerosol suspension in sea water obtained using the CytoFLEX flow cytometer.

Secondly, we can highlight the prevalence of $50 \mu \mathrm{m}$ and $400 \mu \mathrm{m}$ particles in the micron range (Table 3) and the intensive formation of the most toxic 100-200 nm particles (Engin et al., 2017) in the submicron range (Figure 3).

We assumed that underwater welding emission may be toxic to aquatic organisms, and we verified the assumption using the classic embryotoxicity test on sea urchin larvae. The data on the effect of the welding suspension on changes in the development and the viability of sea urchin embryos is presented in Figure 4.

The results demonstrate a linear increase in toxicity of the welding suspension for embryos of sea urchins $S$. mirabilis. We should note an intensive stimulation of development disorders of the embryos that does not lead to a significant increase in mortality up to 24 hours of exposure (Figure $4 \mathrm{a}-\mathrm{c}$ ). After 48 hours of exposure to the maximum concentration of the welding suspension, about a third of the cells died (Figure 4e). Visually, it can be seen in Figure 5. 

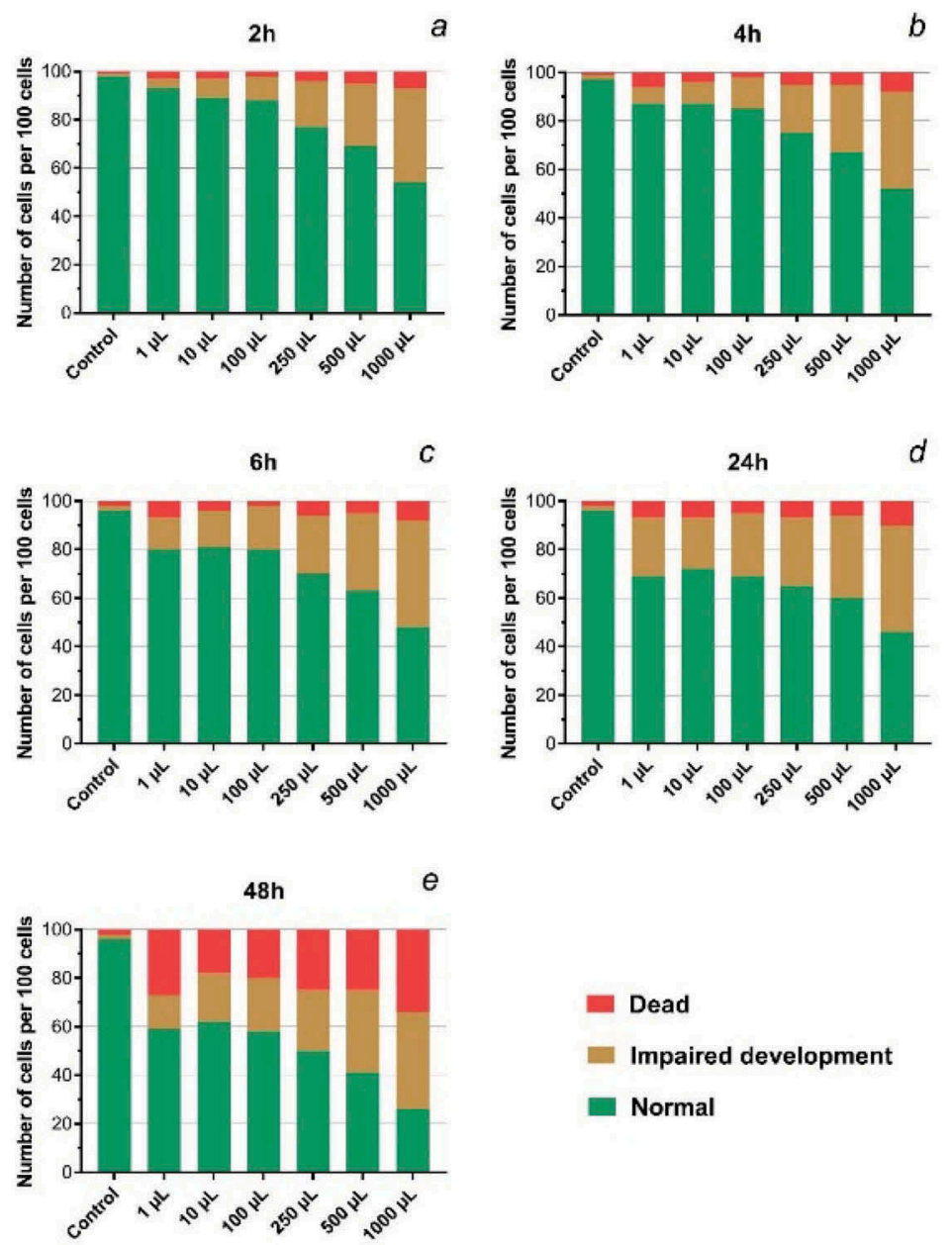

Figure 4. The changes in the development and viability of $S$. mirabilis embryos after the exposure to the welding suspension; $\mathrm{a}-2$-hours treatment, $\mathrm{b}$ - 4-hours treatment, $\mathrm{c}-6$-hours treatment, $\mathrm{d}$ - 24-hours treatment, e-48-hours treatment.
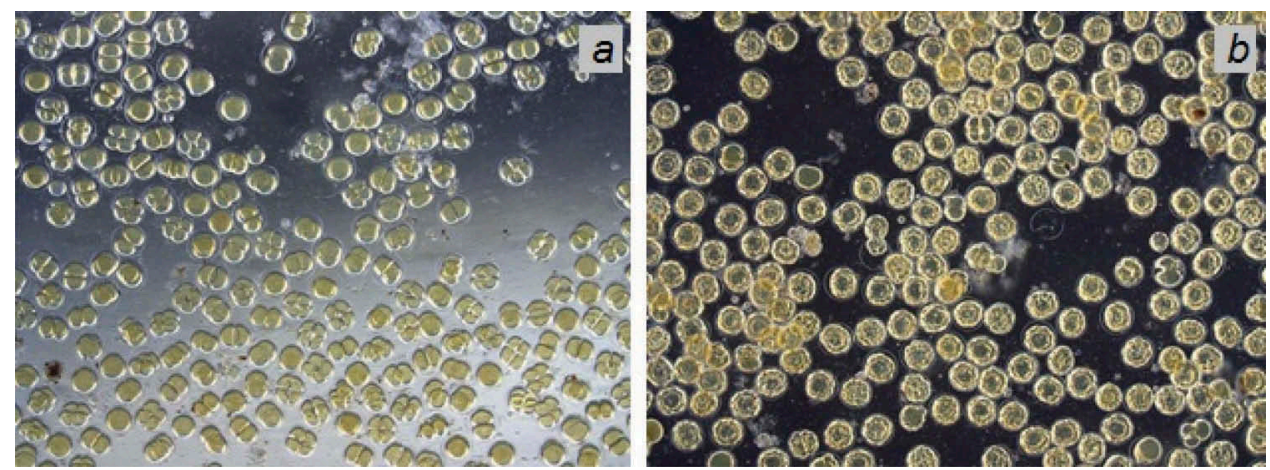

Figure 5. The effect of underwater welding suspension at the concentration of $1000 \mathrm{mg} / \mathrm{L}$ on the embryos of S. mirabilis; a -2-hours treatment, b-48-hours treatment. 


\section{CONCLUSIONS}

The results of this study enable us to state with confidence that underwater welding poses a serious threat to marine ecosystems. Given the growing volume of work on underwater pipelines, which are used for the transportation of natural resources, one should predict an increase of the negative impact on representatives of aquatic organisms. Therefore, this fact requires a timely response. The process of underwater welding needs to be further studied in order to develop ecological standards and effective measures that will ensure safety for the environment and humans.

\section{ACKNOWLEDGEMENTS}

The study was funded by RFBR, project number 19-05-50010, and by the grant from the President of the Russian Federation for young candidates of sciences (PhD) MK-2461.2019.5.

\section{REFERENCES}

Duo, L., Hongliang, L. \& Jical, F. 2015. Chemical core cutting wire for underwater wet method electric arc cutting. Patent $\mathrm{CN} 104858565$ (A).

Duo, L., Ning, G., Yibo, L., Jical, F. \& Xin, Y. 2014. Self-protection flux-cored wire for underwater wetmethod welding. Patent $\mathrm{CN} 104057214$ (A).

Engin, A.B., Neagu, M., Nikitovic, D., Henrich-Noack, P., Docea, A.O., Shtilman, M.I. Golokhvast, K. S. \& Tsatsakis, A.M. 2017. Mechanistic understanding of nanoparticles' interactions with extracellular matrix: the cell and immune system. Particle and Fibre Toxicology 14(1): 22. doi: 10.1186/s12989-0170199-z

Grishanov, A.A. \& Pankov V.I. 1994b. Flux cored wire for welding steels. Patent of the Russian Federation No. 2012469, B23K35/368 (In Russian).

Grishanov, A.A. \& Pankov, V.I. 1994a. Flux cored wire for welding steels. Patent of the Russian Federation No. 2012471, B23K35/368 (In Russian).

Grishanov, A.A. \& Pankov, V.I. 1994c. Flux cored wire for welding steels. Patent of the Russian Federation No. 2012470, B23K35/368 (In Russian).

Han, Y., Dong, S., Zhang, M., Jia, C., Zhang, M. \& Wu, C. 2020. A novel underwater submerged-arc welding acquires sound quality joints for high strength marine steel. Materials Letters 261: 127075. doi:10.1016/j.matlet.2019.127075.

Khrenov, K.K. \& Livshiz, M.L. 1934. Underwater electric arc welding. Svarshchik 6: 26-31. (In Russian).

Kikuchi, M., Syudo, A., Hukumori, M., Naito, C. \& Sawai, J. 2017. Changes in aquatic toxicity of potassium dichromate as a function of water quality parameters. Chemosphere 170: 113-117. doi: 10.1016/j. chemosphere.2016.11.158.

Kirichenko, K., Zakharenko, A., Pikula, K., Chaika, V., Markina, Z., Orlova, T., Medvedev, S., Waissi, G., Kholodov, A., Tsatsakis, A. \& Golokhvast, K. 2019. Dependence of welding fume particle toxicity on electrode type and current intensity assessed by microalgae growth inhibition test. Environmental research 179: 108818. doi: 10.1016/j.envres.2019.108818.

Kroh, A. \& Mooi, R. 2015. The World Echinoidea Database. http://www.marinespecies.org/Echinoidea/.

Labanowski, J., Fydrych, D. \& Rogalski, G. 2008. Underwater welding-a review. Advances in Materials Sciences 8(3): 11-22. doi: 10.2478/v10077-008-0040-3.

Nacci, D., Jackim, E. \& Walsh, R. 1986. Comparative evaluation of three rapid marine toxicity tests: sea urchin early embryo growth test, sea urchin sperm cell toxicity test and Microtox. Environmental Toxicology and Chemistry: An International Journal 5(6): 521-525. doi: 10.1002/etc.5620050603.

Park, J. H., \& Moon, H. S. 2020. Advanced Automatic Welding System for Offshore Pipeline System with Seam Tracking Function. Applied Sciences 10(1): 324. doi: 10.3390/app10010324.

Patlolla, A.K., Barnes, C., Hackett, D. \& Tchounwou, P.B. 2009. Potassium dichromate induced cytotoxicity, genotoxicity and oxidative stress in human liver carcinoma (HepG2) cells. International Journal of Environmental Research and Public Health 6(2): 643-653. doi: 10.3390/ijerph6020643.

Pikula, K.S., Zakharenko, A.M., Chaika, V.V., Stratidakis, A.K., Kokkinakis, M., Waissi, G., Rakitskii, V.N., Sarigiannis, D.A., Hayes A.W., Coleman, M.D., Tsatsakis, A. \& Golokhvast, K.S., 
2019. Toxicity bioassay of waste cooking oil-based biodiesel on marine microalgae. Toxicology Reports 6: 111-117. doi: 10.1016/j.toxrep.2018.12.007.

Wang J., Li W. \& Zhu J. 2012. Flux-cored cutting wire for underwater wet-type arc cutting and preparation method thereof. Patent CN102554520 (A).

Xing, C., Jia, C., Han, Y., Dong, S., Yang, J. \& Wu, C. 2020. Numerical Analysis of the Metal Transfer and Welding Arc Behaviors in Underwater Flux-cored Arc Welding. International Journal of Heat and Mass Transfer 153, 119570. doi: 10.1016/j.ijheatmasstransfer.2020.119570.

Yushchenko, K.A., Fadeeva, G.V., Kakhovsky, Yu.N. \& Savchenko V.S. 1995. Composition of cored wire. Patent of the Russian Federation No. 1605451, bull. No. 3. (In Russian). 